\title{
XXXIII. On the measurement of time-a rejoinder to Dr. N. Campbell
}

\section{Silberstein Ph.D.}

To cite this article: L. Silberstein Ph.D. (1920) XXXIII. On the measurement of time-a rejoinder to Dr. N. Campbell , Philosophical Magazine Series 6, 39:231, 366-372, DOI: 10.1080/14786440308636046

To link to this article: http://dx.doi.org/10.1080/14786440308636046

曲 Published online: 08 Apr 2009.

Submit your article to this journal $₫$

Џ Article views: 5

Q View related articles $₫$ 
XXXIIT. On the Measuremert of Time-a Rejoinder to Dr. N. Campbell. By L. Siribistein, Ph.D., Lecturer in Math. Physics at the University of Rome* .

rTHE paper on "A Time-Scale, etc." by the present writer, published in the September issue of this Magazine, opens the investigation by a statement that the principle of common time-scales amounts to this :-A certain kind of motion (translatory or rotatory) is declared to be a nniform motion; the path is then cut up by means of compasses etc. into a series of equal segments (or angles) and the instants of passige of the molile through the divisions of this metrical scale are taken as $t=0,1,2,3$, and so on.

Dr. N. Campbell, in the November issue of the Phil. Mag. (pp. 652-4), believes "this statement to be untrue." It will be my duty to show that it is true. In the second place, Dr. Campbell believes "still more untrue" (as if truth were liable of gradations) "the statement implied, that timemeasurement is impossible except by some such artificial and elaborate method as he [Silberstein] proposes." Now, concerning this second point, I have not said nor meant to imply that other methods independent of space-measurement were impossible. I simply proposed one, without excluding the possibility of other methods being invented by others. Thus I have nothing more to say about this second point. A third point, however, is that Dr. Campbell offers us his own views on the measurement of time, and these are so palpably unsatisfactory as to require but a few words to be refuted.

But let me first attend to the first point. Now, my statement, quoted at the outset, is not only logically true (that is to say, that a theory of chronometry based on "uniform" motion and patbs or angles carved up into "equal "parts would be a possible logical theory), hut also, which is of groat importance, historically true, the two principles, uniformity and rigid subdivision or transter, being the dominant and basal features of evory practical chronometry since times immemorial and up to, and including, our own lays. In fact, the most ancient measurement of time, as practised by Babylonians, Assyrians, Egyptians, and whom not, was based on the assumption of uniformity of rotation of the heavenly sphere round the Farth, and on a rigid, metrical subdivision of the angles involved in this phenomenon. Massive columns were erected and carefully kept

* Communicated by the Author. 
for this purpose ; later on, up to our days, sun-dials were constructed, and improved with the aid of Euclidean geometry. And the first step (not the last, as Dr. Campbell thinks) was here emphatically the picking out of some grandiose phenomenon and declaring it to go on or to evolve "uniformly," "equably." Nor did these principles of chronometry suffer any serious shock from the great Copernican reform. Somehow our forefinthers chose to declare the Earth's revolution round the Sun and its spinning motion about its own axis as "uniform," and continued to subdivide the associated angles. Manifestly the sm-dials, or their prototypes, continued to show the hours in spite of the modified staudpoint. Yet these natural solar clocks had their bad side, which perhaps is best expressed by the old and beautiful words to be still read on some sun-dials in Italy :

\section{Horas non numero nisi serenas.}

Other time-keepers were, therefore, invented and constructed in very early times, that is to say, even much before Copernicus, whom we mentioned only incidentally-and in all of them the said two features played a dominant role. I do not propose to enumerate here all such old chronometrical devices; nor have I the required historical erudition. But one such device attributed to Alfred the Great, who ruled over the West Saxons (871-901), I cannot pass here in silence, since it seems particularly characteristic in relation to our subject. According to what my little boy heard in his school $*$, Alfred the Great had good tall candles (of what stuff I know not) made for him, and, confiding no doubt in the uniformity of their burning down, dividen them into equal segments, and thus knew the time in day or" night. But apart from the "nisi serenas" condition, the solar clocks had the defect of not being applicable to short time spans (certainly not to our "seconds," and not even to our " minutes"), and the other famous kind of natural time-keepers, the human heart or "pulse," was too often affected by passion or disease to retain permanently the title of uniform (here uniform succession of discrete pulse-beats). Thus the medieval physicist and astronomer bad recourse to a variety of artificial chronometric devices. Even a long time before the Renaissance complicated wheel machines. were constructed as clocks, but none of them was "well regulated" until the times of Galileo and, more especially,

* I have no other means at the moment to verify the historical truth of this report. 
Huyghens. Properly speaking, these "chefs-d'œurre d'agencement cinématique de mouvements," as Jules Andrade calls them, were not " regulated" at all, $i$. e. were felt not to be worth the name of " uniformly going," not keeping pace with the heavenly clock. The now undisputed merit of constructing the first clock in the modern sense of the word is due to Huyghens, although it was Galileo's discovery of the "isochronism" of small pendulum oscillations which he utilised in such an ingenious way. Yet, before Huyghens's invention, Galileo, who was the first to measure comparatively short time-intervals, constructed his own clock for the sake of his famous investigations on falling bodies, a waterclock that is, but more precise than the water-or sand-clocks and the "mechanical" clocks which he inherited from his predecessors. Galileo's own clock is, in the present connexion, as instructive as the burning candle of Alfred the Great. It consisted of a vessel or water-basin of large section having a very small hole in its bottom, to ensure, no doubt, the "uniformity" of the outflow of that liquid. This was his first care. The remainder of the procedure was again in full harmony with our statement; Galileo measured the volume of the water (by weighing it, that is, but this only to make the volume measurements more precise), and he spoke of $t=1,2,3$, etc., as proportional to the number of equal volumes of water; this is equivalent to measuring lengths along the axis of a well-calibrated and narrow cylindrical vessel, if he had one. Galileo's times (the $t$ in his great law $s \sim t^{2}$ ) were proportional to these volumes or ultimately lengths, read on a metrical scale. That the same principles can be instantly traced in all our modern clocks, watches, and chronometers, needs scarcely to be insisted upon.

But they occur perhaps in their purest form in those modern justruments which serve to measure very short times, even down to one-millionth of a second, and perhaps a little less. I have in mind Siemens's high-speed spark chronograpl. It consists, in essence, of a little revolving drum of good steel driven by a carefully finished clock-work. Against this drum, which we used (1897) to cover tightly with a strip of paper blackened with a turpentine lamp soot, is mounted an isolated platinum electrode. Sparks correlated with the events in question pass between the platinum point and the spinning drum and leave marks (little craters) on its blackened surface. The clockwork is then stopped and the drum turned round slowly by a micrometric screw, while the marks are viewed through an appropriately placed microseope. Their angular distance, as read on a subdivided 
circle of the hand-screw, gives the time-interval between spark and spark. "This is the "space-measurement"; and the "uniformity" was most emphatically expressed in a letter of Siemens and Halske accompanying the apparatus, to this effect: If you wish to obtain satisfactory results, do not start the sparks at once but only after the drum was already spinning for a good while, a prescription, no doubt, based upon the makers' dynamical knowledge of the driving machinery, but at any rate a direct appeal to what had to be trusted to be uniform beforehand, without in this case the least possibility of checking the uniformity by investigating, as Dr. Canpbell says in his concluding paragraph, whether the "body covered equal distances in equal times," the "equality" of these minute intervals being in this case not otherwise actually definable, unless one appealed to yet another uniformity, viz. that of the propagation of electromagnetic waves along the wire-systems*. I have dwelt upon this example, not only because it shows the two principles in their neatest form, but also because in writing $m y$ first paper on the time-scale, I had this sparls-chronograph incessantly in my mind. The same remarks can literally be repeated with regard to all the familiar devices in which the drum is replaced by a light rotating mirror used as reflector. Very minute time-intervals are thus being measured and give well consistent results.

But intervals still much shorter, the periods of lightoscillations, are measured again on the same principles. The propagation of light is declared to be uniform, and then linear segments (transiated more or less indirectly on a inagnified seale into an interference pattern) associated with this propagation are measured in the Enclidean fashion. And there is even an ever-growing i priori confidence into the uniformity of light-propagation and a tendency to make it the highest court of appeal for all properly mechanical uniformities.

In short, every precise chronometry is kinematical (motion of bodies or propagation of light), and the foremost concept of kinematics is that of " uniform motion," exactly so as is that of "straight line" in geometry. Both are, theoretically, undefined terms, and in application things are declared to be good approximate samples of either or pointed out (with the finger, as it were)-this or that is uniform, this or that

* The interval between the sparks was, in the application of the chronograph $I$ have in mind, due to the difference of the two corresponding circuits, one rery short and the other about $3 \mathrm{~km}$. long.

Phil. Mag. S. 6. Vol. 39. No. 231. Warch 1920. 2 B 
is straight. 'There is no defining of "straight" nor of " uniform." All so-called definitions of these terms are but apparent, each of them containing a vicious circle.

A definition of uniform motion such as Dr. Campbell repeats after the naive little text-books [to wit: "we define uniform motion as that of a body which covers equal distances in equal times," p. 654] would be exactly as bad as : a straight line is that which slopes down or up (relatively to another straight!) by equal heights in equal horizontal distances. It is precisely such a "definition" which prevents most people from seeing the possibility of non-intersecting, Lobatchevskyan straights and the hypothetical nature of Euclid's parallel axiom. And the kinematical correlata of these things are made manifest in my first paper, showing the possibility of a generalized (hyperbolic) system of kinematics. "he analogy between "uniform" and "straight" becomes still more manifest if one thinks of the modern relativist's four-world, in which a "straight" stands for a space-straight as well as for uniform motion or propagation. But there is no need to appeal to that famous "union" of space and time to show the fundamental, irreducible character of uniform motion; this character belongs to it historically, since times immemorial until our days. Both the assumption of uniformity and the rigid subdivision of the paths or angles are inherent in all the more precise chronometric methods ever devised by man.

This settles the first and chief point of the present note. It is scarcely necessary to add that in declaring such and such a phenomenon to go on uniformly the physicist's, or the astronomer's, choice is, among other things, based upon reasons of convenience, aiming at a certain kind of simplicity of laws or differential equations, such as I attempted to explain in the introductory chapter of the "Theory of Relativity."

The second point being already settled at the very beginning, let us pass at once to our third point, concerning that is Dr. Campbell's own views on the question of the measurement of time. Dr. Campbell is under the fatal misapprehension that he requires but "three definitions" in order to set up a system of measurement of time [nay, of any other magnitude]. These are his (1), (2), and (3), p. 653 . The second concerns only the equality of two time-intervals whose both the beginning and the ends coincide, and the third fixes only, in the usual way, the meaning of the sum of two adjacent (consecutive and gapless) intervals. They nced not detain us any further. The whole burden is loaded 
upon (1) which reads: "The period occupied by the happening of some definite process in a definite system is defined to be 1." Now, if this "definite process" stood for a single particular process covering a single interval of time, obviously nothing could be done with (1), (2), (3). It would amount to as much as giving on a straight a pair of points, $\mathrm{O}$, A, calling $O A$ the "segment 1," and declaring any segment $L N$ to be the sum of the (adjacent) segments $L M$ and $M N$. This would never enable us to say what is a segment 2 , or 3 , and so on.

But, if I well grasp his meaning, Dr. Campbell understands by "definite process," a process such as a fall or a complete oscillation, happening now, or five minutes hence or to-morrow, and so on. This, however, amounts not to solving the problem of measurement, but to massacring it at its very root, or else it amounts to a concealed assumption of uniformity of (in this case) the succession of a discrete set of events. To make my meaning clear, let that standard process be a complete oscillation of a pendulum (to-and-fro) marked by an audible click at its beginning and at its end. Then Dr. Campbell defines all the intervals between a click and the next click as equal to one another, zeroth to first $=$ first to second = fifth to sixth, and so on. But this means either the setting up of an indefinite series of entirely arbitrary time-scale divisions, or else contains the tacit belief in the uniformity of the succession of the clicks. Such a procedure per se would not deserve the name of chronometry; it would be chronoscopy pure and simple. I say, per se, i. e. without relating the pendulum-oscillations to some fundamental kinematical and dynanical principles. With such support the scale would cease to be merely chronoseopic; but then it would indirectly rest upon some continuous uniform motion as the fundamental concept of the very science (mechanics) which is its support. It so, however, then it is preferable to utilize directly a uniform motion (instead of a uniform successioi of discrete clicks), say, a uniform spinning-wbich brings us back to both of our old principles. In fact, Huyghens, who certainly preceded everybody in applying the pendulum to chronometry, used it only as an auxiliary, intervening in his mechanism at discrete instants, and he utilized for rigid subdivision the continuous spinning motion of his wheels. (Such also is the only rôle of the pendulum in eur modern clocks.) That our last remarks are by no means superfuous can be seen from Dr. Campbell's embarrassment when, having dealt very rapidly with "integral numerals," he looks for fractional 
intervals. "The fractions"-he says-"can be obtained by other pendulums," with my italics. Thus, other and other pendulums are to be declared as fresh standards (for instance, for $t=\frac{1}{3}$ we should require a smaller pendulum, such that its three oscillations just fill out the interval between two clicks, for $t=\frac{1}{7}$, yet another, and for what Siemens's chronograph yields, a pendulum of ultra-molecular dimensions); thus the postulate (1) would have to be extended and enriched withont any end. (Moreover, the 'fractional' pendula could only be found by endless trials, for Dr. Campbell's set (1), (2), (3) does not yield a method of constructing the required subdivisions. Nor is, of course, such a scheme adaptable to any somewhat refined chronometry.) Is this satisfactory? Is such a set as Dr. Campbell's (1), (2), (3) satisfactory as the basis, logical or physical, of a theory of time-measurement? I think not.

Moreover, Dr. Campbell believes (1), (2), (3) to be good enough for a theory of the measurement, not only of time, but also of any other "magnitude." He quotes time only as a little example. Now, temperature is certainly an example of "magnitude," and better still, length or distance is another, and it would be extremely interesting to see Dr. Campbell setting up an intrinsic scale in both of these cases, most especially in the latter one.

The psychological clue to all fallacies of Dr. Campbell is contained in his concluding sentence : "Of course, this is all as elementary as A BC." If this were so, gigantic mentalities, such as was Cayley and many of his successors here and abroad, would never have devoted so much time to what is known as the Theory of Distance.

November 4; 1919.

XXXIV. An attempt to determine if Common Lead could be separated into Isotopes by Centrifuging in the Liquid State. By J. Joly, F.R.S., and J. H. J. PoOLe, B.A.I.*

QINCE it has been discovered that both the Uranium and Thorium radioactive families yield elements which are isotopic with ordinary lead but differ from it slightly in atomic weight and density, it has often been suggested that common lead itself is not a homogeneous element, but consists of a mixture of isotopic uranium and thorium lead. This view of the constitution of common lead is based on the fact that

* Communicated by the Authors. 